\title{
MUC2 polymorphisms are associated with endometriosis development and infertility: a case-control study
}

\author{
Cherry Yin-Yi Chang ${ }^{1,2+}{ }^{3}$ Yi Chen ${ }^{3 \dagger}$, Wu-Chou Lin ${ }^{1}$, Chih-Mei Chen ${ }^{3}$, Chih-Ping Chen ${ }^{4}$, Shan-Chih Lee ${ }^{5}$, \\ Jim Jinn-Chyuan Sheu ${ }^{3,6,7^{*}}$ and Fuu-Jen Tsai, ${ }^{3,8^{*}}$
}

\begin{abstract}
Background: Mucins are highly glycosylated proteins protecting and lubricating epithelial surface of respiratory, gastrointestinal and reproductive tracts. Members of the mucin protein family have been suggested to play an important role in development of endometriosis and infertility. This study investigates genetic association of mucin2 (MUC2) with the risk of endometriosis and endometriosis-related infertility.

Methods: This case-control study was conducted at China Medical University Hospital, with 195 endometriosis patients and 196 healthy controls enrolled. Genotyping of six SNPs (rs2856111, rs11245936, rs10794288, rs10902088, rs7103978 and rs11245954) within MUC2 gene were performed by using Taqman genotyping assay; individual SNP and haplotype associations with endometriosis and endometriosis-related infertility were assessed by $\chi^{2}$ test.

Results: Endometriosis patients exhibit significantly lower frequency of the rs $10794288 \mathrm{C}$ allele, the rs $10902088 \mathrm{~T}$ allele and the rs7103978 $\mathrm{G}$ allele ( $P=0.030,0.013$ and 0.040 , respectively). In addition, the rs $10794288 \mathrm{C}$ allele and the rs10902088 T allele were also less abundant in patients with infertility versus fertile ones $(P=0.015$ and 0.024 , respectively). Haplotype analysis of the endometriosis associated SNPs in MUC2 also showed significantly association between the most common haplotypes and endometriosis or endometriosis-related infertility.
\end{abstract}

Conclusions: MUC2 polymorphisms, especially rs 10794288 and rs10902088, are associated with endometriosis as well as endometriosis-related infertility. Our data present MUC2 as a new candidate involved in development of endometriosis and related infertility in Taiwanese Han women.

\section{Background}

Endometriosis is a common chronic gynecologic disease defined as presence of endometrial tissue outside the uterine cavity, primarily on pelvic peritoneum and ovary. Epidemiology studies reveal that endometriosis affects more than $10 \%$ of reproductive age women and possibly causes infertility $[1,2]$. The prevalence of endometriosis was $0.5-5 \%$ in fertile and $25-45 \%$ in infertile women [3]. The mechanism underlying endometriosis development remains unclear, even though theories like implantation, altered immunity, and susceptible genetic factors have been proposed to explain the pathogenesis

\footnotetext{
* Correspondence: jimsheu@mail.cmu.edu.tw; d0704@mail.cmuh.org.tw + Contributed equally

${ }^{3}$ Human Genetics Center, China Medical University Hospital, 2 Yude Road, 40447 Taichung, Taiwan

Full list of author information is available at the end of the article
}

[4-6]. Nevertheless, familial and identical twins studies have established the genetic predisposition to endometriosis development [7].

Clinical manifestation of endometriosis is accompanied by angiogenesis and formation of cellular adhesion $[8,9]$, possibly due to altered peritoneal environment and immune system [10]. In endometriosis patients, changes in levels of growth factors, cytokines and oncofetal antigens may facilitate intraperitoneal endometrial growth and alter the peritoneal environment, which leads to disruption of normal pelvic organ architectures and infertility [8]. For instance, interluekin-1 (IL-1), interleukin-6 (IL-6), interleukin-8 (IL-8), interleukin-10 (IL-10), nuclear factor $-\kappa \mathrm{B}(\mathrm{NF}-\kappa \mathrm{B})$ and tumor necrosis factoralpha (TNF- $\alpha$ ) are among the major cytokines participating in regulation of immune system, angiogenesis,
C Biomed Central

() 2012 Chang et al; licensee BioMed Central Ltd. This is an Open Access article distributed under the terms of the Creative Commons Attribution License (http://creativecommons.org/licenses/by/2.0), which permits unrestricted use, distribution, and reproduction in any medium, provided the original work is properly cited. 
cell proliferation and tissue invasiveness during the formation of endometriosis [11-14].

Mucins are high molecular weight glycoproteins with function of protecting and lubricating epithelial surface of respiratory, gastrointestinal and reproductive tracts [15]. Mucins are also found to be expressed on activated lymphocytes, supporting the hypothesis that some mucin domains function as cytokines to mediate immune responses [16,17]. Early studies reported that mucin played important role in the progress of tumor invasion, which is influenced by their glycosylation status [15,18-20]. More recently, mucin1 (MUC1) has been reported to be linked to endometriosis and infertility [21,22], and mucin4 (MUC4) gene polymorphisms were proved to be associated with endometriosis development as well [23]. The human mucin2 (MUC2) gene is located on chromosome 11p15.5, encoding one of the most common gel-forming secreted type of mucin [24]. MUC2 expression was reported to be regulated by many endometriosis-related cytokines, such as IL-1 $\beta$, IL-6, TNF- $\alpha$, NF-Kappa B [9,25-27]. Abnormal increase of mucin2 (MUC2) expression was reported to be linked to intestinal and uterine cervix metaplasia progression $[28,29]$.

However, there has been no study yet investigating the relationship between endometriosis and MUC2, while previous functional studies on MUC2 are more focused on its role in the gastrointestinal and respiratory tract $[30,31]$.

The aim of this study was to investigate the possible association of $M U C 2$ gene polymorphisms with the risk of endometriosis and endometriosis-related clinical symptoms in a Taiwanese population.

\section{Methods}

\section{Subjects}

In all, 195 patients receiving surgery for ovarian benign disease and pathology-proven endometriosis patients were identified at China Medical University Hospital from 1998-2011 and enrolled in the study. They accepted examination of ultrasound before operation and were diagnosed with ovarian cysts; symptoms of dysmenorrhea, lower abdominal pain, infertility or abnormal menstruation were recorded for each patient. Another 196 healthy controls were recruited from a pool of persons who received regular health checkups at the same hospital. People with ovarian cysts detected by ultrasound or any symptoms of dysmenorrhea, lower abdominal pain, infertility, abnormal menstruation were excluded from the controls. Both patients and controls share similar age profile. Clinical information of patients was collected from medical charts, including clinical stage, lesion size, location, drug treatment and fertility. The definition of endometriosis staging was based on criteria of the American Society for Reproductive Medicine: stage 1 , minimal; stage 2 , mild; stage 3 , moderate; and stage 4 , severe [32]. Individual leukocytes were drawn by vein-puncture and separated by Ficoll-paque (GE, Uppsala, Sweden) for genomic DNA isolation. Signed consent was obtained from each study subject, approved by the Institutional Review Board at China Medical University Hospital.

\section{Genotyping}

Genomic DNA was extracted from peripheral blood leukocytes according to standard protocol (Genomic DNA kit; Qiagen, Valencia, CA, USA). DNA fragments containing target SNP sites were amplified by PCR using the Taqman SNP genotyping assay system from Applied Biosystems, Inc. (Carlsbad, CA, USA). The probe IDs for these SNP sites were selected from the ABI SNP genotyping databank http://www.allsnps.com and listed in Additional file 1: Table S1. PCR amplification conditions consisted of initial denaturation at $95^{\circ} \mathrm{C}$ for $5 \mathrm{~min}$, followed by 40 cycles of $95^{\circ} \mathrm{C}$ for $10 \mathrm{sec}$, and $56^{\circ} \mathrm{C}$ for $10 \mathrm{sec}$. Genetic variations were detected by reading the fluorescence signals of PCR products. A positive fluorescent signal indicates a perfect match between the probe and the tested DNA, thus identifying the allele type.

\section{Statistical analysis}

Allelic and genotypic frequency distributions for these SNP sites in endometriosis patients and controls were performed by $\chi^{2}$ analysis using SPSS software (version 10.0, SPSS Inc. Chicago, Illinois, US). Allelic and genotypic frequencies are expressed as percentages of the total number of alleles and genotypes. Odds Ratios (ORs) were calculated for allelic and genotypic frequencies with $95 \%$ confident interval $(95 \% \mathrm{CI})$. Adherence to the Hardy-Weinberg equilibrium constant was confirmed by $\chi^{2}$ test with one degree of freedom by PLINK program [33].

Haplotype association was analyzed using Bayesian statistical method available in the program Phase 2.1 [34]. Lewontin's coefficient D' and the linkage disequilibrium (LD) were determined between each pairs of biallelic loci using absolute association $\left(r^{2}\right)$ [35]. Haploview 4.2 (Whitehead Institute for Biomedical Research, Cambridge, MA) was used to examine the structure of the LD block [36]. A $p$ value of less than 0.05 was considered statistically significant.

\section{Functional analyses and secondary structure prediction}

Functional characterization and annotation of MUC2 were performed by aligning the sequence with functional motifs in PROSITE protein domain database [37]. NetSurfP ver. 1.1 was used to predict the secondary structure and surface accessibility of MUC2 [38] Relative 
and absolute surface accessibility were also calculated for each residue.

\section{Results \\ MUC2 polymorphisms and endometriosis}

To test whether SNPs in MUC2 gene play role in endometriosis development, a total of six SNPs were selected for this study, with minor allelic frequencies over $4 \%$ in Chinese Han population based on the information in international HapMap project databank http://www.hapmap.org (Additional file 1: Table S1). These SNPs and their LD map were shown in Figure 1A. Genotype and allele frequencies were summarized in Table 1 for both the patient and the control groups. Allele distribution analyses revealed significant associations between endometriosis and genetic variations at three of the six SNPs (Table 1). Endometriosis patients had significantly lower frequencies of $\mathrm{C}$ allele at rs 10794288, $\mathrm{T}$ allele at rs10902088 and G allele at rs7103978, as compared to the controls $(P=0.030,0.013$ and 0.040 , respectively) (Table 1). Genotype analysis indicated that frequency of the TT genotype at rs10902088 was significantly lower in patients than in controls $(P=0.045$; OR $=0.47,95 \%$ CI: 0.27-0.83), while the CC genotype at rs10794288 and the AG genotype at rs7103978 had protective effect against endometriosis $(\mathrm{OR}=0.56$ and 0.47 , respectively; 95\% CI < 1) (Table 1). These results implied possible relationship between three individual $M U C 2$ polymorphisms and endometriosis development.

\section{MUC2 polymorphisms and infertility}

Because endometriosis was suggested as one source of female infertility, we asked whether genetic variations in $M U C 2$ play roles in this process. The patients were subgrouped into patients with infertility or without infertility for genotype and allele distribution analyses. Patients without sexual experience were excluded in this study. As shown in Table 2, the C allele at rs10794288

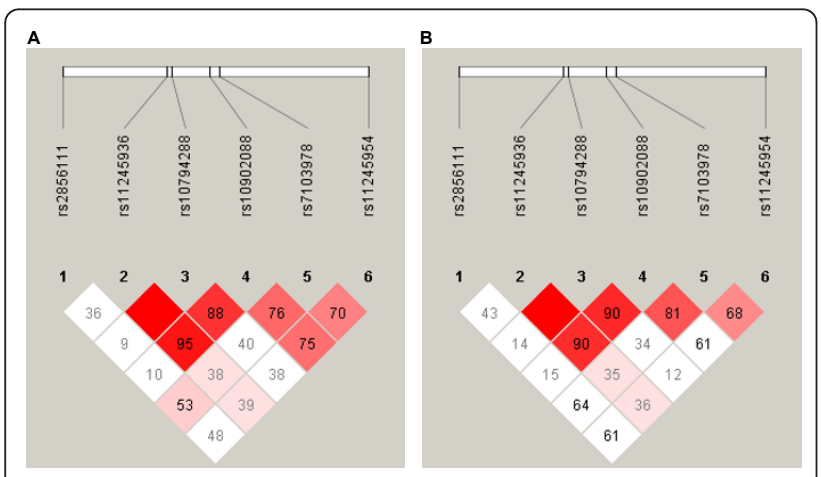

Figure 1 Pairwise linkage disequilibrium (LD) between SNPs of the MUC2 gene. LD maps were shown for controls (A) and patients (B). Values shown are for D'. and the $\mathrm{T}$ allele at rs10902088 were much less prevalent in patients with infertility $(P=0.015$ and 0.024 , respectively). The TT genotype at rs 10902088 were absent in the infertile patient group, and genotype distribution was also significantly different between the infertile and the fertile patients for this SNP $(P=0.047$, data not shown). This finding revealed protective potential of these two genetic variations in $M U C 2$ against infertility in endometriosis patients.

\section{Haplotype analysis of $M U C 2$ polymorphisms}

The endometriosis-related SNPs (rs10794288, rs10902088 and rs7103978) found in individual tests were selected for haplotype analysis of endometriosis and disease-related clinical symptoms. Association data were enlisted in Table 3 for all the haplotypes with frequency higher than $1 \%$ presented in the case or control group. As shown in Table 3, the two most common haplotypes ( $\mathrm{T}-\mathrm{C}$ and $\mathrm{C}-\mathrm{T}$ ) of rs10794288 and rs10902088 were significantly associated with both endometriosis and infertility development in the patients. Haplotype T-C was more common in endometriosis patients $(P=0.012)$ and patients with infertility $(P=0.0091)$ (Table 3$)$. By contrast, haplotype C-T might be a protective factor against endometriosis $(P=$ $0.035)$ and endometriosis-related infertility $(P=0.025)$ (Table 3). Similarly, the most frequent haplotype T-C-A of rs10794288, rs10902088 and rs7103978 was significantly associated with both endometriosis $(P=0.0063)$ and endometriosis-related infertility $(P=0.0066)$ as a risk factor of the disease (Table 3 ). In the patient group, LD map demonstrated higher linkage between these three SNPs (Figure 1B) compared to the control group (Figure 1A), suggesting a genetic relationship between these SNPs and endometriosis. Therefore, haplotypes of these SNPs in $M U C 2$ gene could serve as an indicator of susceptibility to endometriosis and endometriosisrelated infertility.

\section{MUC2 polymorphisms and amino acid substitutions}

One of the endometriosis-associated SNPs (rs1090 2088) in MUC2 gene caused an amino acid substitution (Additional file 1: Table S1), and functions of MUC2 might be altered if such substitution changes surface charge, protein stability or folding. This SNP located at amino acid Asn1149, which was predicted to be within a long coil region. The relative surface accessibility of Asn 1149 was estimated to be 0.707 with reference to a fully exposed side chain, representing a highly exposed residue. Genetic variation of rs10902088 introduced an asparagine to lysine substitution, which was well fit in this position as a highly exposed residue, but the surface charge at this region would be reversed. Accordingly, this substitution was 
Table 1 Association between SNPs in MUC2 gene and endometriosis in Taiwanese patients and controls

\begin{tabular}{|c|c|c|c|c|c|c|c|c|}
\hline \multirow{2}{*}{$\frac{\text { SNP }}{\text { rs2856111 }}$} & \multirow{2}{*}{$\frac{\text { Genotype/allele }}{\text { CC }}$} & \multicolumn{2}{|c|}{ No. (\%) of patients } & \multicolumn{2}{|c|}{ No. (\%) of controls } & \multirow{2}{*}{$\frac{p \text {-value }}{0.29}$} & \multirow{2}{*}{$\begin{array}{c}\text { OR } \\
0.79\end{array}$} & \multirow{2}{*}{$\begin{array}{c}95 \% \mathrm{Cl} \\
0.46-1.36\end{array}$} \\
\hline & & 35 & $(18.5)$ & 35 & $(18.2)$ & & & \\
\hline & $\mathrm{CT}$ & 96 & $(50.8)$ & 111 & $(57.8)$ & & 0.69 & $0.43-1.10$ \\
\hline & $\pi$ & 58 & $(30.7)$ & 46 & $(24.0)$ & & 1.00 & \\
\hline & C & 166 & (43.9) & 181 & $(47.1)$ & 0.37 & 0.88 & $0.66-1.17$ \\
\hline & $\mathrm{T}$ & 212 & $(56.1)$ & 203 & (52.9) & & 1.00 & \\
\hline \multirow[t]{5}{*}{ rs11245936 } & AA & 1 & $(0.5)$ & 3 & $(1.6)$ & 0.34 & 0.32 & $0.03-3.10$ \\
\hline & $A G$ & 21 & $(11.0)$ & 28 & $(14.5)$ & & 0.72 & $0.39-1.32$ \\
\hline & GG & 169 & $(88.5)$ & 162 & (83.9) & & 1.00 & \\
\hline & A & 23 & $(6.0)$ & 34 & $(8.8)$ & 0.14 & 0.66 & $0.38-1.22$ \\
\hline & G & 359 & $(94.0)$ & 352 & $(91.2)$ & & 1.00 & \\
\hline \multirow[t]{5}{*}{ rs10794288 } & $\mathrm{CC}$ & 34 & $(17.4)$ & 45 & $(23.0)$ & 0.092 & 0.56 & 0.33-0.96 \\
\hline & CT & 87 & $(44.6)$ & 96 & $(49.0)$ & & 0.67 & $0.43-1.06$ \\
\hline & $\pi$ & 74 & $(37.9)$ & 55 & $(28.0)$ & & 1.00 & \\
\hline & C & 155 & (39.7) & 186 & $(47.4)$ & $0.030^{*}$ & 0.73 & 0.55-0.97 \\
\hline & $\mathrm{T}$ & 235 & $(60.3)$ & 206 & (52.6) & & 1.00 & \\
\hline \multirow[t]{5}{*}{ rs10902088 } & $\pi$ & 27 & (14.0) & 43 & (22.3) & $0.045^{*}$ & 0.47 & $0.27-0.83$ \\
\hline & $\mathrm{CT}$ & 93 & $(48.2)$ & 95 & $(49.2)$ & & 0.74 & $0.47-1.16$ \\
\hline & $C C$ & 73 & (37.8) & 55 & (28.5) & & 1.00 & \\
\hline & $\mathrm{T}$ & 147 & (38.1) & 181 & $(47.4)$ & $0.013^{*}$ & 0.70 & $0.52-0.93$ \\
\hline & C & 239 & (61.9) & 205 & (52.6) & & 1.00 & \\
\hline \multirow[t]{5}{*}{ rs7103978 } & GG & 2 & $(1.0)$ & 1 & $(0.5)$ & 0.053 & 1.84 & $0.16-21.58$ \\
\hline & $A G$ & 19 & $(9.8)$ & 37 & (18.9) & & 0.47 & $0.26-0.85$ \\
\hline & $\mathrm{AA}$ & 172 & (89.1) & 158 & (80.6) & & 1.00 & \\
\hline & G & 23 & $(6.0)$ & 39 & $(9.9)$ & $0.040^{*}$ & 0.57 & $0.34-0.98$ \\
\hline & A & 363 & $(94.0)$ & 353 & $(90.1)$ & & 1.00 & \\
\hline \multirow[t]{5}{*}{ rs11245954 } & GG & 0 & $(0.0)$ & 0 & $(0.0)$ & NA & NA & NA \\
\hline & $A G$ & 21 & (10.8) & 26 & (13.5) & & 0.78 & $0.42-1.43$ \\
\hline & $\mathrm{AA}$ & 173 & $(89.2)$ & 166 & (86.5) & & 1.00 & \\
\hline & G & 21 & $(5.4)$ & 26 & $(6.8)$ & 0.43 & 0.79 & $0.44-1.43$ \\
\hline & A & 367 & (94.6) & 358 & $(93.2)$ & & 1.00 & \\
\hline
\end{tabular}

*Indicates statistical significance

${ }^{\text {a }} P$-values were calculated using $\chi^{2}$ test without corrections for multiple test

more likely to disrupt inter- or intra-molecular interactions of MUC2 rather than protein stability. On the other hand, rs10794288 and rs7103978 were silent mutations, which only influence codon usages instead of amino acid substitutions.

Table 2 Association between allele distributions of SNPs in MUC2 and endometriosis-related infertility

\begin{tabular}{llllll}
\hline SNP & $\begin{array}{l}\text { Infertile } \\
\text { MAF }\end{array}$ & $\begin{array}{l}\text { Non-Infertile } \\
\text { MAF }\end{array}$ & $\boldsymbol{P}_{\text {-value }}{ }^{a}$ & OR & 95\% Cl \\
\hline rs2856111 & 48.1 & 41.3 & 0.36 & 1.32 & $0.73-2.38$ \\
rs11245936 & 3.8 & 5.4 & 0.64 & 0.70 & $0.16-3.16$ \\
rs10794288 & 24.1 & 41.7 & $0.015^{*}$ & 0.44 & $0.23-0.87$ \\
rs10902088 & 26.0 & 43.1 & $0.024^{*}$ & 0.46 & $0.24-0.91$ \\
rs7103978 & 5.8 & 5.8 & 0.99 & 0.99 & $0.28-3.54$ \\
rs11245954 & 3.8 & 4.7 & 0.79 & 0.82 & $0.18-3.72$ \\
\hline
\end{tabular}

*Indicates statistical significance

MAF minor allele frequency

${ }^{\mathrm{a}} P$-values were calculated using $\chi 2$ test

\section{Discussion}

Mucin proteins were known to be heavily glycosylated, on which oligosaccharide structures turned to be tumor-associated antigens and are essential for antibody recognition [39-41]. Our data revealed two MUC2 polymorphisms (rs10794288 and rs10902088) were associated with endometriosis development and the related infertility. Polymorphism at rs 10902088 generates an amino-acid change Asn1149Lys, while rs10794288 is a silent substitution. Although Asn1149 is not a typical site for N-linked glycosylation, this substitution to positively charged residue may influence the glycosylation states of several neighboring serines and Asn1154, which is within a typical $\mathrm{N}$-linked glycosylation tripeptide sequon Asn-Ile-Ser [42]. Therefore, this polymorphism may alter the glycosylation status of MUC2, which may subsequently influence the interaction between MUC2 and host environments. 
Table 3 Association between MUC2 haplotypes and endometriosis or endometriosis-related infertility

\begin{tabular}{|c|c|c|c|c|c|c|c|}
\hline \multirow[t]{2}{*}{ SNP marker } & \multirow[t]{2}{*}{ Haplotype } & \multicolumn{3}{|c|}{ Endometriosis } & \multicolumn{3}{|c|}{ Endometriosis-related infertility } \\
\hline & & Case (\%) & Control (\%) & $P$-value ${ }^{a}$ & Infertility (\%) & Non-infertility (\%) & $P$-value ${ }^{a}$ \\
\hline \multirow[t]{4}{*}{ rs10794288, rs10902088 } & $\mathrm{T}-\mathrm{C}$ & 58.6 & 49.6 & $0.012^{*}$ & 74.9 & 57.2 & $0.0091^{*}$ \\
\hline & $C-T$ & 35.8 & 43.2 & $0.035^{*}$ & 23.4 & 38.3 & $0.025^{*}$ \\
\hline & $C-C$ & 3.4 & 3.7 & 0.83 & 0.1 & 2.6 & 0.20 \\
\hline & $\mathrm{T}-\mathrm{T}$ & 2.1 & 3.5 & 0.27 & 1.6 & 1.9 & 0.89 \\
\hline \multirow[t]{5}{*}{ rs10794288, rs10902088, rs7103978 } & $\mathrm{T}-\mathrm{C}-\mathrm{A}$ & 57.8 & 48.1 & $0.0063^{*}$ & 74.8 & 56.3 & $0.0066^{*}$ \\
\hline & C-T-A & 32.0 & 35.9 & 0.25 & 22.0 & 34.1 & 0.06 \\
\hline & C-T-G & 3.8 & 7.2 & $0.036^{*}$ & 1.4 & 4.2 & 0.29 \\
\hline & $C-C-A$ & 3.4 & 3.7 & 0.81 & 0 & 2.6 & 0.20 \\
\hline & T-T-G & 1.5 & 2.0 & 0.61 & 1.6 & 1.1 & 0.76 \\
\hline
\end{tabular}

*Indicates statistical significance. aP-values were calculated using $\chi 2$ test

Endometriosis development is associated with altered inflammatory and immune responses, while clinical feature of endometriosis also mimics malignant reproductive disease, such as progressive invasion to adherent pelvic organ and recurrence abilities. Mucins are secreted by epithelium cells of reproductive tissues, generating the mucus of cervix and endometrium, which plays an important role in reproductive physiology. Impaired mucin secretion could impede spermatozoa migration, which may contribute to female infertility. Unlike the less consistent expression patterns of MUC1, MUC6 and MUC5AC in normal and cancer tissues, MUC2 levels were always measured low in normal endometrial and cervical tissue, and elevated MUC2 expressions were specifically found in various neoplastic lesions [28,29,43-45]. However, expression patterns of MUC2 in ovarian tumor were heterogenic [18]. Boman et al. reported that MUC2 were mainly present in benign and borderline ovarian tumor [46], while Dong et al. showed that breast cancer patients with presence of MUC2 expression had shorter disease-free survival [47]. We found that the minor allele of rs7103978 decreases the cognate codon frequency from $15.8 \%$ to 7.8\%o (Kazusa DNA Res. Inst. http://www.kazusa.or.jp/ codon/), which may increase the odds of premature translation termination and thus reduce MUC2 level. Therefore, our result suggested that expression of MUC2 may facilitate cell invasion or proliferation abilities. The observed association of $M U C 2$ polymorphisms and endometriosis may help us further elucidate the link between endometriosis and certain subtypes of ovarian cancer, if such genetic alterations were also present in the ovarian cancer patients.

Although endometriosis could cause pelvic adhesion and tubal occlusion which lead to infertility, some patients without anatomic disruption still had the problem of impaired fertilization. Possible mechanisms of endometriosis-related infertility include impaired folliculogenesis induced by abnormal immunological, chemical factors or toxins, poor oocyte quality, inhibited binding of spermatozoa to the zona-pellucida and impaired implantation of embryo. This phenomenon was correlated to changes of cytokines and growth factors in endometrium, follicular fluid and peritoneal fluid [8]. Previous studies have already showed the positive association of endometriosis and polymorphism of cytokine genes $[7,48]$. Li et al. showed that macrophage induced IL-6 up-regulated the MUC1 but down-regulated MUC2 expression [9]. Up-regulation of MUC1 was associated with implantation failure [22]. IL-1 was also found to up-regulate MUC2 expression, and IL-1 was thought to regulate immune and inflammation response in endometrium and modulate extracellular matrix modeling of endometrium during menstruation and implantation [49]. Moreover, previous studies demonstrated that IL-8, TNF $-\alpha$ and NF- $\kappa$ B tend to increase in the peritoneal fluid according to the severity of dysmenorrhea, extent pelvic adhesion and proliferation of endometrial stroma cells, and MUC2 expression could increase accordingly via activation of NF- $\kappa \mathrm{B}$ pathway through these cytokines [50-52]. Therefore, it is plausible that altered level of MUC2 could affect fertility as a downstream effecter that can further influence the secretion of mucus, sperm motility, oocyte quality and receptivity of endometrium.

\section{Conclusions}

In this study, our data revealed a significant association between $M U C 2$ polymorphisms and endometriosis in a Taiwanese population. The results imply that MUC2 may play a role in the pathogenesis of endometriosis and endometriosis-related infertility, while the mechanisms underlying this phenomenon remain to be elucidated. As a major secreted form of mucins, MUC2 may have the ability to affect more surrounding tissues than the membrane-bound form of mucins. Since MUC2 is not as well investigated as some other mucins in reproductive organs, its molecular function in endometriosis and infertility is worth future study. 


\section{Additional material}

Additional file 1: Table S1. Probes been used for SNPs in MUC2 gene.

\section{Acknowledgements}

We appreciate the kind assistance from Ms Carmen Chan at China Medical University Hospital. This work was supported by the grant from China Medical University Hospital (DMR-99-091) and the China Medical UniversityAsia University Research Collaboration Fund (CMU98-asia-02), Taichung, Taiwan.

\section{Author details}

'Department of Obstetrics and Gynecology, China Medical University Hospital, 2 Yude Road, 40402 Taichung, Taiwan. ${ }^{2}$ Institute of Public Health, China Medical University, 91 Hsueh-Shih Road, 40447 Taichung, Taiwan. ${ }^{3}$ Human Genetics Center, China Medical University Hospital, 2 Yude Road, 40447 Taichung, Taiwan. ${ }^{4}$ Department of Obstetrics and Gynecology, Mackay Memorial Hospital, 92 Sec. 2 Zhongshan Road, 10449 Taipei, Taiwan. ${ }^{5}$ School of Medical Imaging and Radiological Sciences, Chung Shan Medical University, 110 Sec.1 Jianguo N. Rd, 40201 Taichung, Taiwan. ${ }^{6}$ School of Chinese Medicine, China Medical University, 91 Hsueh-Shih Road, 40447 Taichung, Taiwan. ${ }^{7}$ Department of Health and Nutrition Biotechnology, Asia University, 500 Lioufeng Road, 41354 Taichung, Taiwan. ${ }^{8}$ School of PostBaccalaureate Chinese Medicine, China Medical University, 91 Hsueh-Shih Road, 40447 Taichung, Taiwan.

\section{Authors' contributions}

CY-YC and YC: study design, execution and manuscript drafting; YC and CMC: statistical analysis; CY-YC, W-CL and F-JT: patient collection; C-PC, S-CL and JJ-CS: critical discussion and manuscript editing. All authors read and approved the final manuscript.

\section{Competing interests}

The authors declare that they have no competing interests.

Received: 17 October 2011 Accepted: 15 March 2012

Published: 15 March 2012

\section{References}

1. Ballard $\mathrm{K}$, Lowton $\mathrm{K}$, Wright J: What's the delay? A qualitative study of women's experiences of reaching a diagnosis of endometriosis. Fertil Steril 2006, 86(5):1296-1301.

2. Bhattacharya S, Porter M, Amalraj E, Templeton A, Hamilton M, Lee AJ, Kurinczuk JJ: The epidemiology of infertility in the North East of Scotland. Hum Reprod 2009, 24(12):3096-3107.

3. Ozkan S, Murk W, Arici A: Endometriosis and infertility: epidemiology and evidence-based treatments. Ann N Y Acad Sci 2008, 1127:92-100.

4. Vercellini P, Somigliana E, Vigano P, Abbiati A, Barbara G, Fedele L: 'Blood On The Tracks' from corpora lutea to endometriomas. BJOG 2009, 116(3):366-371.

5. Stefansson $H$, Geirsson RT, Steinthorsdottir $V$, Jonsson $H$, Manolescu A, Kong A, Ingadottir G, Gulcher J, Stefansson K: Genetic factors contribute to the risk of developing endometriosis. Hum Reprod 2002, 17(3):555-559.

6. Lebovic DI, Mueller MD, Taylor RN: Immunobiology of endometriosis. Fertil Steril 2001, 75(1):1-10.

7. Falconer $\mathrm{H}, \mathrm{D}^{\prime}$ Hooghe $\mathrm{T}$, Fried $\mathrm{G}$ : Endometriosis and genetic polymorphisms. Obstet Gynecol Surv 2007, 62(9):616-628.

8. Gupta S, Goldberg JM, Aziz N, Goldberg E, Krajcir N, Agarwal A: Pathogenic mechanisms in endometriosis-associated infertility. Fertil Steril 2008, 90(2):247-257

9. Li YY, Hsieh LL, Tang RP, Liao SK, Yeh KY: Macrophage-derived interleukin6 up-regulates MUC1, but down-regulates MUC2 expression in the human colon cancer HT-29 cell line. Cell Immunol 2009, 256(1-2):19-26.

10. Christodoulakos G, Augoulea A, Lambrinoudaki I, Sioulas V, Creatsas G: Pathogenesis of endometriosis: the role of defective 'immunosurveillance'. Eur J Contracept Reprod Health Care 2007, 12(3):194-202
11. Gonzalez-Ramos R, Van Langendonckt A, Defrere S, Lousse JC, Colette S, Devoto L, Donnez J: Involvement of the nuclear factor-kappaB pathway in the pathogenesis of endometriosis. Fertil Steril 2010, 94(6):1985-1994.

12. Kyama CM, Overbergh L, Debrock S, Valckx D, Vander Perre S, Meuleman C, Mihalyi A, Mwenda JM, Mathieu C, D'Hooghe TM: Increased peritoneal and endometrial gene expression of biologically relevant cytokines and growth factors during the menstrual phase in women with endometriosis. Fertil Steril 2006, 85(6):1667-1675.

13. Pellicer A, Albert C, Mercader A, Bonilla-Musoles F, Remohi J, Simon C: The follicular and endocrine environment in women with endometriosis: local and systemic cytokine production. Fertil Steril 1998, 70(3):425-431

14. Carlberg M, Nejaty J, Froysa B, Guan Y, Soder O, Bergqvist A: Elevated expression of tumour necrosis factor alpha in cultured granulosa cells from women with endometriosis. Hum Reprod 2000, 15(6):1250-1255.

15. Yonezawa S, Goto M, Yamada N, Higashi M, Nomoto M: Expression profiles of MUC1, MUC2, and MUC4 mucins in human neoplasms and their relationship with biological behavior. Proteomics 2008, 8(16):3329-3341.

16. Agrawal B, Krantz MJ, Parker J, Longenecker BM: Expression of MUC1 mucin on activated human T cells: implications for a role of MUC1 in normal immune regulation. Cancer Res 1998, 58(18):4079-4081.

17. Correa I, Plunkett T, Vlad A, Mungul A, Candelora-Kettel J, Burchell JM, Taylor-Papadimitriou J, Finn OJ: Form and pattern of MUC1 expression on $\mathrm{T}$ cells activated in vivo or in vitro suggests a function in T-cell migration. Immunology 2003, 108(1):32-41.

18. Tornos C, Soslow R, Chen S, Akram M, Hummer AJ, Abu-Rustum N, Norton L, Tan LK: Expression of WT1, CA 125, and GCDFP-15 as useful markers in the differential diagnosis of primary ovarian carcinomas versus metastatic breast cancer to the ovary. Am J Surg Pathol 2005, 29(11):1482-1489.

19. Gendler SJ, Lancaster CA, Taylor-Papadimitriou J, Duhig T, Peat N, Burchell J, Pemberton L, Lalani EN, Wilson D: Molecular cloning and expression of human tumor-associated polymorphic epithelial mucin. J Biol Chem 1990, 265(25):15286-15293

20. Williams SJ, McGuckin MA, Gotley DC, Eyre HJ, Sutherland GR, Antalis TM: Two novel mucin genes down-regulated in colorectal cancer identified by differential display. Cancer Res 1999, 59(16):4083-4089.

21. Vlad AM, Diaconu I, Gantt KR: MUC1 in endometriosis and ovarian cancer. Immunol Res 2006, 36(1-3):229-236.

22. Horne AW, Lalani EN, Margara RA, Ryder TA, Mobberley MA, White JO: The expression pattern of MUC1 glycoforms and other biomarkers of endometrial receptivity in fertile and infertile women. Mol Reprod Dev 2005, 72(2):216-229.

23. Chang CY, Chang HW, Chen CM, Lin CY, Chen CP, Lai CH, Lin WY, Liu HP, Sheu JJ, Tsai FJ: MUC4 gene polymorphisms associate with endometriosis development and endometriosis-related infertility. BMC Med 2011, 9:19.

24. Gum JR Jr, Hicks JW, Toribara NW, Siddiki B, Kim YS: Molecular cloning of human intestinal mucin (MUC2) cDNA. Identification of the amino terminus and overall sequence similarity to prepro-von Willebrand factor. J Biol Chem 1994, 269(4):2440-2446.

25. Ahn DH, Crawley SC, Hokari R, Kato S, Yang SC, Li JD, Kim YS: TNF-alpha activates MUC2 transcription via NF-kappaB but inhibits via JNK activation. Cell Physiol Biochem 2005, 15(1-4):29-40.

26. Kim YD, Jeon JY, Woo HJ, Lee JC, Chung JH, Song SY, Yoon SK, Baek SH: Interleukin-1beta induces MUC2 gene expression and mucin secretion via activation of PKC-MEK/ERK, and PI3K in human airway epithelial cells. J Korean Med Sci 2002, 17(6):765-771.

27. Iwashita J, Sato Y, Sugaya H, Takahashi N, Sasaki H, Abe T: mRNA of MUC2 is stimulated by IL-4, IL-13 or TNF-alpha through a mitogen-activated protein kinase pathway in human colon cancer cells. Immunol Cell Biol 2003, 81(4):275-282.

28. Babu SD, Jayanthi V, Devaraj N, Reis CA, Devaraj H: Expression profile of mucins (MUC2, MUC5AC and MUC6) in Helicobacter pylori infected preneoplastic and neoplastic human gastric epithelium. Mol Cancer 2006, $5: 10$

29. Riethdorf L, O'Connell JT, Riethdorf S, Cviko A, Crum CP: Differential expression of MUC2 and MUC5AC in benign and malignant glandular lesions of the cervix uteri. Virchows Arch 2000, 437(4):365-371.

30. Kim YS, Ho SB: Intestinal goblet cells and mucins in health and disease: recent insights and progress. Curr Gastroenterol Rep 2010, 12(5):319-330. 
31. Voynow JA, Gendler SJ, Rose MC: Regulation of mucin genes in chronic inflammatory airway diseases. Am J Respir Cell Mol Biol 2006, 34(6):661-665.

32. Revised American Society for Reproductive Medicine classification of endometriosis: 1996. Fertil Steril 1997, 67(5):817-821.

33. Purcell S, Neale B, Todd-Brown K, Thomas L, Ferreira MA, Bender D, Maller J, Sklar P, de Bakker PI, Daly MJ, et al: PLINK: a tool set for whole-genome association and population-based linkage analyses. Am J Hum Genet 2007, 81(3):559-575.

34. Stephens M, Donnelly P: A comparison of bayesian methods for haplotype reconstruction from population genotype data. Am J Hum Genet 2003, 73(5):1162-1169.

35. Hedrick PW: Gametic disequilibrium measures: proceed with caution. Genetics 1987, 117(2):331-341.

36. Barrett JC, Fry B, Maller J, Daly MJ: Haploview: analysis and visualization of LD and haplotype maps. Bioinformatics 2005, 21(2):263-265.

37. Sigrist CJ, Cerutti L, Hulo N, Gattiker A, Falquet L, Pagni M, Bairoch A, Bucher P: PROSITE: a documented database using patterns and profiles as motif descriptors. Brief Bioinform 2002, 3(3):265-274.

38. Petersen B, Petersen TN, Andersen P, Nielsen M, Lundegaard C: A generic method for assignment of reliability scores applied to solvent accessibility predictions. BMC Struct Biol 2009, 9:51.

39. Magnani JL, Steplewski Z, Koprowski H, Ginsburg V: Identification of the gastrointestinal and pancreatic cancer-associated antigen detected by monoclonal antibody 19-9 in the sera of patients as a mucin. Cancer Res 1983, 43(11):5489-5492.

40. Goldenberg DM, Pegram CA, Vazquez JJ: Identification of a colon-specific antigen (CSA) in normal and neoplastic tissues. J Immunol 1975, 114(3):1008-1013.

41. Gendler SJ, Burchell JM, Duhig T, Lamport D, White R, Parker M, TaylorPapadimitriou J: Cloning of partial cDNA encoding differentiation and tumor-associated mucin glycoproteins expressed by human mammary epithelium. Proc Natl Acad Sci USA 1987, 84(17):6060-6064.

42. Jones J, Krag SS, Betenbaugh MJ: Controlling N-linked glycan site occupancy. Biochim Biophys Acta 2005, 1726(2):121-137.

43. Levi E, Klimstra DS, Andea A, Basturk O, Adsay NV: MUC1 and MUC2 in pancreatic neoplasia. J Clin Pathol 2004, 57(5):456-462.

44. Jankovic Velickovic L, Katic V, Hattori T, Kushima R, Marjanovic G, Stefanovic V: Differences in the expression of mucins in various forms of cystitis glandularis. Pathol Res Pract 2007, 203(9):653-658.

45. Ho SB, Niehans GA, Lyftogt C, Yan PS, Cherwitz DL, Gum ET, Dahiya R, Kim YS: Heterogeneity of mucin gene expression in normal and neoplastic tissues. Cancer Res 1993, 53(3):641-651.

46. Boman F, Buisine MP, Wacrenier A, Querleu D, Aubert JP, Porchet N: Mucin gene transcripts in benign and borderline mucinous tumours of the ovary: an in situ hybridization study. J Pathol 2001, 193(3):339-344.

47. Dong Y, Walsh MD, Cummings MC, Wright RG, Khoo SK, Parsons PG, McGuckin MA: Expression of MUC1 and MUC2 mucins in epithelial ovarian tumours. J Pathol 1997, 183(3):311-317.

48. Poliness AE, Healey MG, Brennecke SP, Moses EK: Proteomic approaches in endometriosis research. Proteomics 2004, 4(7):1897-1902.

49. Kim YD, Kwon EJ, Park DW, Song SY, Yoon SK, Baek SH: Interleukin-1 beta induces MUC2 and MUC5AC synthesis through cyclooxygenase-2 in $\mathrm{NCl}-$ H292 cells. Mol Pharmacol 2002, 62(5):1112-1118.

50. Sakamoto $Y$, Harada T, Horie S, Iba Y, Taniguchi F, Yoshida S, Iwabe T, Terakawa N: Tumor necrosis factor-alpha-induced interleukin-8 (IL-8) expression in endometriotic stromal cells, probably through nuclear factor-kappa B activation: gonadotropin-releasing hormone agonist treatment reduced IL-8 expression. J Clin Endocrinol Metab 2003, 88(2):730-735.

51. Grund EM, Kagan D, Tran CA, Zeitvogel A, Starzinski-Powitz A, Nataraja S, Palmer SS: Tumor necrosis factor-alpha regulates inflammatory and mesenchymal responses via mitogen-activated protein kinase kinase, p38, and nuclear factor kappaB in human endometriotic epithelial cells. Mol Pharmacol 2008, 73(5):1394-1404

52. Wu J, Gong J, Geng J, Song Y: Deoxycholic acid induces the overexpression of intestinal mucin, MUC2, via NF-kB signaling pathway in human esophageal adenocarcinoma cells. BMC Cancer 2008, 8:333.

\section{Pre-publication history}

The pre-publication history for this paper can be accessed here: http://www.biomedcentral.com/1471-2350/13/15/prepub

doi:10.1186/1471-2350-13-15

Cite this article as: Chang et al:: MUC2 polymorphisms are associated with endometriosis development and infertility: a case-control study. BMC Medical Genetics 2012 13:15.

\section{Submit your next manuscript to BioMed Central and take full advantage of:}

- Convenient online submission

- Thorough peer review

- No space constraints or color figure charges

- Immediate publication on acceptance

- Inclusion in PubMed, CAS, Scopus and Google Scholar

- Research which is freely available for redistribution

Submit your manuscript at www.biomedcentral.com/submit
C Biomed Central 